\title{
Prediction of casing wear in extended-reach drilling
}

\author{
Gao Deli'*, Sun Lianzhong ${ }^{1}$ and Lian Jihong ${ }^{2}$ \\ ${ }^{1}$ Key Laboratory of Petroleum Engineering, Ministry of Education, China University of Petroleum, Beijing 102249, China \\ ${ }^{2}$ CACT Operators Group, Shenzhen, Guangdong 518069, China
}

(C) China University of Petroleum (Beijing) and Springer-Verlag Berlin Heidelberg 2010

\begin{abstract}
Intermediate casings in the build sections are subject to severe wear in extended-reach drilling. This paper presents a new method for predicting the depth of a wear groove on the intermediate casing. According to energy principle and dynamic accumulation of casing wear by tool joints, a model is established to calculate the wear area on the inner wall of the casing. The relationship functions between the wear groove depth and area are obtained based on the geometry relationship between the drillstring and the wear section and the assumption that the casing wear groove is crescent-shaped. The change of casing wear groove depth versus drilling footage under different-sized drillstrings is also discussed. A mechanical model is proposed for predicting casing wear location, which is based on the well trajectory and drillstring movement. The casing wear groove depth of a planned well is predicted with inversion of the casing wear factor from the drilled well and necessarily revised to improve the prediction accuracy for differences between the drilled well and the planned well. The method for predicting casing wear in extended-reach drilling is verified through actual case study. The effect of drillstring size on casing wear should be taken into account in casing wear prediction.
\end{abstract}

Key words: Extended-reach drilling, casing wear, casing wear location, inversion calculation

\section{Introduction}

In extended-reach drilling (ERD), contacts between the drillstring and the casing leads to excessive casing wear, which might cause a series of accidents and even result in huge economic losses. Therefore, it is important to predict casing wear so as to optimize the material grade and wall thickness of the casing and/or install pipe protectors for ERD operations (Gao et al, 2009). This can improve drilling safety, reduce accidents, save drilling costs, and prolong the life of oil \& gas wells.

Several researchers have conducted a lot of laboratory measurements and field tests to establish casing wear models. Bradley and Fontenot (1975) presented a means of estimating the casing wear based on an experimentally determined casing wear rate. The wear rate is approximately proportional to the contact force. Compared with the wear coefficients derived from laboratory wear measurements for rotating, tripping, and running wireline, drillstring rotation is a major cause of the casing wear. On the basis of extensive experimental testing, Williamson (1981) found that the contact pressure between the tool joints and the casing wear groove rather than the contact load is the parameter controlling the casing wear rate due to tool joint rotation. And another conclusion

*Corresponding author. email: gaodeli@cup.edu.cn

Received September 7, 2009 can be drawn that an increase in contact points of the same outer diameter (OD) as the tool joints can reduce the casing wear. White and Dawson (1987) presented a wear-efficiency model which relates casing-metal removal to the amount of energy dissipated by friction in the wear process. This model is recognized as relatively sound and efficient for wear prediction at present. To apply this model to a wide range of drilling situations, Hall et al (1994) performed over 300 laboratory wear tests to determine wear factors. Double or quadruple wear factors obtained from laboratory tests are used to compensate for the probable underestimation of the dogleg severity in the field. On the basis of an exponential equation obtained from data of more than 475 8-hour wear tests of casings and risers, Hall and Malloy (2005) proposed the concept of a contact pressure threshold to estimate the ultimate wear groove depth, which means the casing wear can be self-limiting so that the maximum wear groove depth will not increase regardless of the elapsed drilling time. Generally, the ultimate casing wear groove depth may increase without limit. Yu et al (2004) investigated the even wear of the casing caused by drillstring rotation, with Archard's wear equation in combination with the wear-efficiency model.

Casing wear is mainly associated with contact force and sliding distance between the drillstring and the casing, which are constantly changing as the drillstring is being extended in the hole. Now the average method is widely used, that is, the casing wear is caused by average contact force of drill pipe 
at the average value of revolutions per minute (RPM), rate of penetration (ROP), weight on drill bit (WOB), and a given drilling footage. A dynamic cumulative approach is used to describe these factors more accurately in this paper.

The simulation of casing wear in the laboratory and the caliper recording in oil fields show that there are at least two stages: transient wear and steady-state wear of the casing (Schoenmakers, 1987; Hall and Malloy, 2005). Due to the shorter transient casing wear time but higher wear factor, the casing wear factor (CWF) value obtained from the total volume loss and sliding distance covered would be greatly in the error if the casing test time is not long enough (Yang, 2005). In addition, the calculation accuracy of the contact force between the drillstring and the casing still needs further research and improvement, and the calculation error of contact force will make the casing wear prediction error larger. However, inversion of CWF in a drilled well can overcome the above shortcomings and accord with the actual drilling situations of friction and casing wear.

Schoenmakers (1987) found that working with two different-sized drillstrings results in double running-in wear, which aggravates the casing wear. He attributed this phenomenon to running-in wear and did not investigate other potential reasons. Williamson (1981) believed that the higher contact pressure and thus the wear rate for a given load would result in the faster casing wear if the diameters of tool joints passing the casing wear point varied during drilling. The authors hold that the size changes of tool joints would affect the worn casing geometry and thus the casing wear groove depth (CWGD). Therefore, it is necessary to study the effect of sizes of drillstring on casing wear, which has great significance on casing wear prediction in ERD.

As the drilling footage extends, the contact point between the drillstring and the casing changes and it is likely that the wear location is not unique for the casing cross-section at a given depth. Therefore, this issue involves how to estimate the casing wear volume effectively. In accordance with threedimensional (3D) trajectory and movement of drillstring, a model of casing wear location is established. Through the quantitative calculation of the wear location angle and the dynamic estimation of the casing wear area in the same wear location, the casing wear prediction can be achieved at any measured depth.

Based on the above research, CWF and other important parameters are obtained through inversion of the actual drilling data and the caliper recording for the adjacent drilled extended reach well (ERW), and then calculation can be done satisfactorily for the casing wear prediction of the planned ERW in which the casing program is similar to the drilled well in the same zone.

\section{Prediction model of casing wear}

The wear of materials in sliding contacts can be explained by the dissipated energy due to friction between both contacting parts (White and Dawson, 1987; Huq and Celis, 2002), and different wear mechanisms agree with Archard's model only with different meanings of the wear factor (Archard, 1980). Therefore, the wear-efficiency model widely used in casing wear prediction currently can be developed as a modified version of Archard's model. Casing wear is mainly due to the rotation of tool joints and the effect of pipe reciprocation can be neglected in the tripping process (Bradley and Fontenot, 1975). The volume of casing worn away can be expressed as follows (White and Dawson, 1987; Tan et al, 2006):

$$
V=\frac{\eta}{H_{\mathrm{b}}} \int \mu N L \mathrm{~d} l=f_{\mathrm{w}} \int \mu N L \mathrm{~d} l
$$

where $V$ is the volume of metal removed by wear, $\mathrm{m}^{3} ; H_{\mathrm{b}}$ is the casing Brinell hardness, $N / \mathrm{m}^{2} ; \eta$ is the wear efficiency, dimensionless; $f_{\mathrm{w}}$ is the casing wear factor, $1 / \mathrm{Pa} ; N$ is the contract force between the drillstring and casing, $\mathrm{N} / \mathrm{m}$; $L$ is the distance slid, $\mathrm{m} ; \mu$ is the circumferential friction coefficient, dimensionless.

The casing wear area is:

$$
\begin{aligned}
S & =\frac{\mathrm{d} V}{\mathrm{~d} l}=f_{\mathrm{w}} \mu N L=f_{\mathrm{w}} \mu N \pi N_{\mathrm{R}} D_{\mathrm{tj}} \\
& =60 \pi f_{\mathrm{W}} \mu n D_{\mathrm{tj}} N \frac{L_{\mathrm{M}}}{R O P}
\end{aligned}
$$

where $S$ is the casing wear area, $\mathrm{m}^{2} ; N_{\mathrm{R}}$ is the number of revolutions, dimensionless; $D_{\mathrm{tj}}$ is the outer diameter of the tool joint, $\mathrm{m} ; n$ is the revolution rate of the rotary table, $\mathrm{r} / \mathrm{min}$; $R O P$ is the rate of penetration, $\mathrm{m} / \mathrm{h} ; L_{\mathrm{M}}$ is the drilling footage, $\mathrm{m}$.

At a given drilling footage, the casing wear area due to all of the tool joints through the same casing position can be estimated:

$$
S=60 \pi f_{\mathrm{w}} \mu L_{\mathrm{s}} \sin \alpha \sum_{i=1}^{m} \frac{q_{i} D_{\mathrm{t} j i} n_{i}}{R O P_{i}}
$$

In a $3 \mathrm{D}$ hole, the calculation method for contact force between the drillstring and the casing can be found in the literature (Gao, 2006).

In a two-dimensional (2D) crooked hole and a onedimensional (1D) inclined hole, the analytical solutions to contact force can be obtained, thus the analytical solutions to casing wear area can be obtained with the dynamic cumulative approach. We define that the sign of the radius curvature is positive in the build sections and negative in the drop sections, the axial load of drillstring is positive under compression and negative under tension, and the contact force between the drillstring and the wellbore is positive when the drillstring contacts the low side of the wellbore otherwise it is negative. The wear at the high side or low side of the wellbore should be calculated respectively once the direction of contact force reverses.

In a straight inclined wellbore, the contact force is related to the gravity component, and then the casing wear area is expressed as follows:

$$
S=60 \pi f_{\mathrm{w}} \mu L_{\mathrm{s}} \sin \alpha \sum_{i=1}^{m} \frac{q_{i} D_{\mathrm{t} j i} n_{i}}{R O P_{i}}
$$

where $L_{\mathrm{S}}$ is the drill pipe span, $\mathrm{m} ; m$ is the number of spans, $m=L_{\mathrm{M}} / L_{\mathrm{S}}$, rounded to an integer; $\alpha$ is the tangent section angle, degrees; $q_{i}$ is the effective weight per unit length of the $i$ th pipe through to the end of build curve (EOB) or end of 
drop curve (EOD), $\mathrm{N} / \mathrm{m} ; R O P_{i}$ is the rate of penetration at the footage from $(i-1) L_{\mathrm{S}}$ to $i L_{\mathrm{S}}, \mathrm{m} / \mathrm{h} ; n_{i}$ is the revolution rate of the rotary table corresponding to $R O P_{i}, \mathrm{r} / \mathrm{min}$.

When drilling at a constant RPM and with the same type of drill pipes, the casing wear area in the 1D wellbore is:

$$
S=60 \pi f_{\mathrm{w}} \mu q \sin \alpha D_{\mathrm{tj}} n \frac{L_{\mathrm{M}}}{R O P}
$$

Drag \& torque models of drillstring (Gao, 2006) indicate that under a given WOB the axial load applied to the tool joint at a specified distance from the drill bit in the crooked wellbore is related to the drillstring length, inclination angle, effective pipe weight, and wellbore curvature. Since the axial force and contact force vary regularly with the distance between joints and the drill bit, the casing wear area also varies regularly. When the direction of contact force remains unchanged, the casing wear area can be expressed as follows:

$$
\begin{aligned}
& S_{j}=60 \pi f_{\mathrm{W}} \mu L_{\mathrm{S}} \times \\
& \sum_{i=1}^{m} \frac{D_{\mathrm{t} j i} n_{i}}{R O P_{i}}\left[\left(\frac{F_{j}}{R}+q_{i} \sin \alpha_{i}\right)-\sum_{k=1}^{i-1} \frac{q_{k}}{R} L_{\mathrm{S}}\left(\cos \alpha-\mu^{\prime} \sin \alpha\right)\right]
\end{aligned}
$$

When the same type of drill pipes is used to drill the wellbore under the virtually unchanged RPM, ROP and WOB, the casing wear in crooked wellbores can be presented as:

$$
\begin{aligned}
& S_{j}=\frac{60 \pi D_{\mathrm{tj}} n f_{\mathrm{W}} \mu L_{\mathrm{S}}}{R O P} \times \\
& {\left[m N_{j}-\frac{m(m-1)}{2} \frac{q}{R} L_{\mathrm{S}}\left(\cos \alpha-\mu^{\prime} \sin \alpha\right)\right]}
\end{aligned}
$$

where $S_{j}$ is the wear area of the $j$ th casing span above EOB or EOD, $\mathrm{m}^{2} ; F_{j}$ is the axial force, $\mathrm{N} ; R$ is the curvature radius of the wellbore, $\mathrm{m} ; N_{j}$ is the initial contact force of the $j$ th drillstring span above the EOB or EOD at the beginning of penetration, $\mathrm{N} / \mathrm{m} ; u^{\prime}$ is the axial friction coefficient, dimensionless.

\section{CWGD calculation}

The casing wear surface can be seen as an intersection of the casing inner wall with the tool joint, which takes two forms; a single wear groove or a composite wear groove. The composite wear groove may be sharp crescent-shaped and blunt crescent-shaped, the former is caused by a smaller tool joint than the previous one and the later formed by a greater one than the previous. Therefore, three cases of the casing wear were analyzed respectively in this paper, which include the single, the sharp and the blunt crescent-shaped groove. Supposed that $R_{\mathrm{tj}}$ and $r_{\mathrm{tj}}$ stand for the outer radius of two adjacent tool joints and $R_{\mathrm{tj}}$ is greater than $r_{\mathrm{tj}}$ in the following analysis.

More complicated worn casing geometries would be formed by more OD changes of tool joints, but CWGD analysis is the same as the above three cases.

\subsection{Single crescent-shaped casing wear}

From graphics relations (see Fig. 1), the maximum CWGD can be expressed as follows:

$$
\begin{aligned}
& D_{\mathrm{W}}=a-R_{\mathrm{ci}}+R_{\mathrm{tj}} \\
& d=\sqrt{R_{\mathrm{ci}}^{2}-\frac{\left(R_{\mathrm{ci}}^{2}+a^{2}-R_{\mathrm{tj}}^{2}\right)^{2}}{4 a^{2}}}
\end{aligned}
$$

where $D_{\mathrm{W}}$ is the maximum casing wear groove depth, $\mathrm{m} ; a$ is the eccentricity of the tool joint, $\mathrm{m} ; R_{\mathrm{ci}}$ is the inner radius of the casing, $\mathrm{m}$.

The wear area of the casing is derived by integration over its crescent-shaped wear groove. The expression is expressed as follows:

$$
\begin{aligned}
S & =2 \int_{0}^{d}\left(a+\sqrt{R_{\mathrm{tj}}^{2}-x^{2}}-\sqrt{R_{\mathrm{ci}}^{2}-x^{2}}\right) \mathrm{d} x \\
& =R_{\mathrm{tj}}^{2} \arcsin \frac{d}{R_{\mathrm{tj}}}-R_{\mathrm{ci}}^{2} \arcsin \frac{d}{R_{\mathrm{ci}}}+d a
\end{aligned}
$$

If the inner diameter (ID) of the casing and the OD of the tool joint are available, a quadratic polynomial fitting function $S=c_{0}+c_{1} a+c_{2} a^{2}$ is used to calculate CWGD approximately and the calculation error $\Delta$ may be eliminated or reduced by the iteration method. According to the actual situation, there is only one reasonable solution. The maximum CWGD can be expressed as:

$$
D_{\mathrm{W}}=\frac{-c_{1}+\sqrt{c_{1}^{2}-4 c_{2}\left(c_{0}-S\right)}}{2 c_{2}}-R_{\mathrm{ci}}+R_{\mathrm{tj}}-\Delta
$$

where $\Delta$ is the calculation error of casing wear groove depth, m.

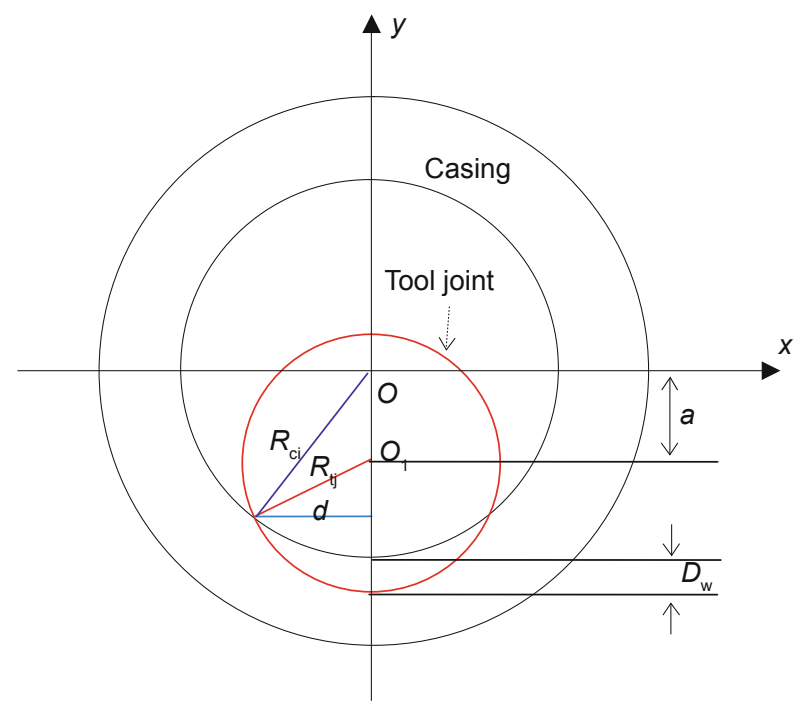

Fig. 1 Worn casing geometry

\subsection{Sharp crescent-shaped casing wear}

This case involves the issue of a critical width of casing wear groove that is the width of a groove caused by the previous tool joint.

While the critical width is less than the width of the newly formed wear groove on the casing, the total area of the 
groove can be calculated by the crescent-shaped intersection between the tool joint with a radius of $r_{\mathrm{tj}}$ and the inner wall of the casing, and CWGD calculation is the same as that for the single crescent-shaped casing wear.

The following discussion will focus on CWGD calculations when the width of the newly formed wear groove does not exceed the critical width of the casing wear groove.

The maximum depth of the original casing wear groove caused by the first tool joint is:

$$
D_{\mathrm{w} 1}=a_{1}-R_{\mathrm{ci}}+R_{\mathrm{tj}}
$$

and the ultimate CWGD is:

$$
D_{\mathrm{W} 2}=a_{2}+r_{\mathrm{tj}}-R_{\mathrm{ci}}
$$

where $a_{1}$ is the eccentricity of the first tool joint with a radius of $R_{\mathrm{tj}}$ and $a_{2}$ is the eccentricity of the second tool joint with a radius of $r_{\mathrm{tj}}$.

The half width of the newly formed casing wear groove is expressed as follows:

$$
d_{2}=\sqrt{R_{\mathrm{tj}}^{2}-\left(\frac{r_{\mathrm{tj}}^{2}-R_{\mathrm{tj}}^{2}-\left(a_{2}-a_{1}\right)^{2}}{2\left(a_{1}-a_{2}\right)}\right)^{2}}
$$

and the newly formed wear area $S_{2}$ equals the area of a crescent-shaped intersection by two tool joints with different sizes, which can be expressed as follows:

$$
\begin{aligned}
S_{2} & =2 \int_{0}^{d_{2}}\left(\sqrt{r_{\mathrm{tj}}^{2}-x^{2}}-\sqrt{R_{\mathrm{tj}}^{2}-x^{2}}+a_{2}-a_{1}\right) \mathrm{d} x \\
& =r_{\mathrm{tj}}^{2} \arcsin \frac{d_{2}}{r_{\mathrm{tj}}}-R_{\mathrm{tj}}^{2} \arcsin \frac{d_{2}}{R_{\mathrm{tj}}}+\left(a_{2}-a_{1}\right) d_{2}
\end{aligned}
$$

There is only one unknown parameter $a_{2}$ and then the ultimate CWGD $D_{\mathrm{W} 2}$ can be obtained by the iterative method.

\subsection{Blunt crescent-shaped casing wear}

In this case, the width of the newly formed casing wear groove is more than that of the original casing wear groove from beginning to end, but there is a critical area of casing wear to decide whether the CWGD increases or not. When the total wear area is less than the critical area, the CWGD will not increase but the width of casing wear groove will increase. If the total wear area is more than the critical area, the CWGD can be calculated just like that for the single crescent-shaped wear. The critical casing wear area $S_{\mathrm{c}}$ can be expressed as follows:

$$
\begin{aligned}
a_{\mathrm{c}} & =D_{\mathrm{w} 1}+R_{\mathrm{ci}}-R_{\mathrm{tj}} \\
d_{3} & =\sqrt{R_{\mathrm{ci}}^{2}-\frac{\left(R_{\mathrm{ci}}^{2}+a_{\mathrm{c}}^{2}-R_{\mathrm{tj}}^{2}\right)^{2}}{4 a_{\mathrm{c}}^{2}}} \\
S_{\mathrm{c}} & =2 \int_{0}^{d_{3}}\left(a_{\mathrm{c}}+\sqrt{R_{\mathrm{tj}}^{2}-x^{2}}-\sqrt{R_{\mathrm{ci}}^{2}-x^{2}}\right) \mathrm{d} x \\
& =R_{\mathrm{tj}}^{2} \arcsin \frac{d_{3}}{R_{\mathrm{tj}}}-R_{\mathrm{ci}}^{2} \arcsin \frac{d_{3}}{R_{\mathrm{ci}}}+a_{\mathrm{c}} d_{3}
\end{aligned}
$$

\subsection{Effect of drillstring size on casing wear}

In order to analyze the change of CWGD with drilling footage under different-sized drillstring, the $ø 244.5 \mathrm{~mm}$ casing wear (ID of $220.5 \mathrm{~mm}$ ) in the horizontal section was predicted using the data of drill pipes as shown in Table 1. Let $R O P=10 \mathrm{~m} / \mathrm{h}, R P M=120 \mathrm{rpm}$, and $C W F=4.0 \times 10^{-12} \mathrm{~Pa}^{-1}$. The analytical results are shown in Fig. 2.

Table 1 Drill pipes for analyzing casing wear

\begin{tabular}{ccccc}
\hline Drill pipe & $\begin{array}{c}\text { OD } \\
\mathrm{mm}\end{array}$ & $\begin{array}{c}\text { Max. OD } \\
\mathrm{mm}\end{array}$ & $\begin{array}{c}\text { ID } \\
\mathrm{mm}\end{array}$ & $\begin{array}{c}\text { Effective weight } \\
\mathrm{N} / \mathrm{m}\end{array}$ \\
\hline Drill pipe 1 & 127.0 & 139.7 & 108.6 & 244.9 \\
Drill pipe 2 & 139.7 & 177.8 & 121.4 & 318.3 \\
\hline
\end{tabular}

There are two stages including the running-in wear and steady-state wear on the curve of CWGD versus drilling footage, without considering non-linear changes of the casing wear volume for a single size of drill pipes. Another runningin wear pattern arises when sizes of drill pipe changes at a footage of 3,000 $\mathrm{m}$ in the sharp crescent-shaped wear, which makes the casing wear aggravated within a certain footage. The new running-in wear is largely due to the shape changes of the casing wear groove, in other words, it will not vanish if the conditions of friction \& wear are unchanged. And there is a stage that CWGD does not increase with the footage in blunt crescent-shaped casing wear, which alleviates the casing wear within a certain footage.

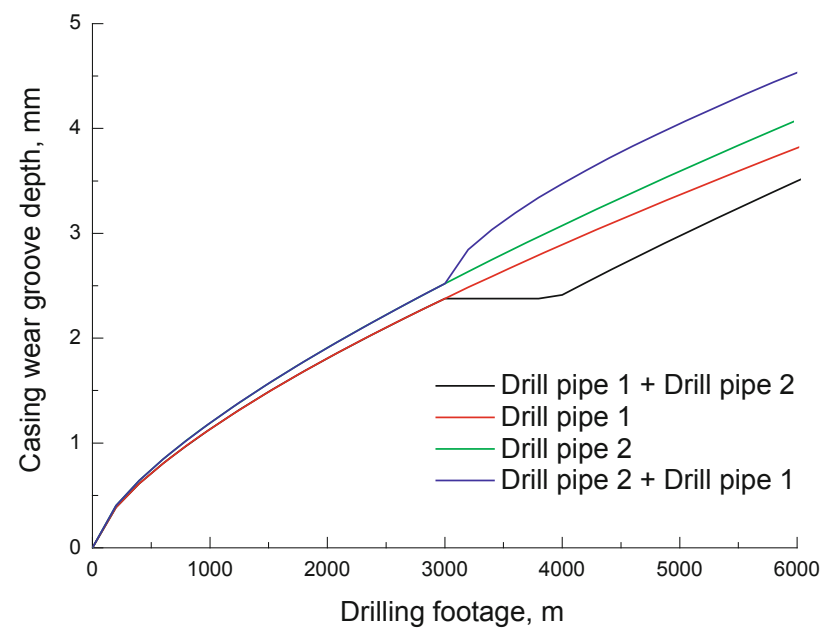

Fig. 2 Effect of drillstring size on CWGD

\section{Calculation of casing wear location}

To determine the wear location in the casing string, a wear location angle is defined as the clockwise rotation angle from the high side direction of wellbore to the contact direction between the pipe and casing (Fig. 3). For the principal normal, binormal, high side direction, and the contact direction are all located in the same plane, the included angles between these vectors can be easily calculated. It is easy for 
us to find the calculation method for the principal normal and binormal of wellbore trajectory in the related references (Gao and $\mathrm{Xu}, 1991$; Juvkam-Wold and Wu, 1992).

The high side direction is described by the following unit vector $\boldsymbol{h}$ :

$$
\begin{aligned}
\boldsymbol{h} & =h_{i j}\left[\left(\sin \theta_{1} \sin \phi_{1}+\sin \theta_{2} \sin \phi_{2}\right) \boldsymbol{i}\right. \\
& \left.+\left(\sin \theta_{1} \cos \phi_{1}+\sin \theta_{2} \cos \phi_{2}\right) \boldsymbol{j}\right]+\sin \bar{\theta} \boldsymbol{k}
\end{aligned}
$$

where $h_{i j}=\cos \bar{\theta} / \sqrt{2(1+\cos \beta)-\left(\cos \theta_{1}+\cos \theta_{2}\right)^{2}}$, which is positive in conventional wells and negative in those wells in which the true vertical depth decreases as the measured depth increases; $\theta$ is the inclination angle, degrees; $\bar{\theta}$ is the average inclination angle, degrees; $\Phi$ is the azimuth angle, degrees; the subscripts 1 and 2 denote the upper end and the lower end; $\beta$ is the total angle change, degrees.

The angle between the high side unit-vector and the binormal unit-vector is defined as $\gamma_{\text {mh }}$ that is positive as the high side unit-vector rotates clockwise to the binormal unitvector.

$$
=\arccos \frac{\sin \theta_{1} \sin \theta_{2} \sin \left(\phi_{1}-\phi_{2}\right)\left[h_{i j}\left(\cos \theta_{1}+\cos \theta_{2}\right)+\sin \bar{\theta}\right]}{\sin \beta}
$$

$N_{\text {dp }}$ and $N_{\mathrm{p}}$ are the total lateral loads $(\mathrm{N} / \mathrm{m})$ respectively in the dogleg plane and in the direction perpendicular to the dogleg plane so that the contact direction between the drillstring and casing can be determined by the sizes and directions of these two forces, and the angle between the binormal unit-vector and the contact direction becomes the following expression:

$$
\begin{aligned}
& \text { When } \gamma_{\mathrm{mh}} \geq \frac{\pi}{2} \\
& \left\{\begin{array}{l}
\gamma_{\mathrm{pm}}=-\arcsin \left|\frac{N_{\mathrm{dp}}}{N}\right|, \quad N_{\mathrm{dp}}<0 \\
\gamma_{\mathrm{pm}}=\arcsin \left|\frac{N_{\mathrm{dp}}}{N}\right|, \quad N_{\mathrm{dp}}>0
\end{array}\right.
\end{aligned}
$$

when $\gamma_{\mathrm{mh}}<\frac{\pi}{2}$

$$
\left\{\begin{array}{l}
\gamma_{\mathrm{pm}}=\pi+\arcsin \left|\frac{N_{\mathrm{dp}}}{N}\right|, N_{\mathrm{dp}}<0 \\
\gamma_{\mathrm{pm}}=\pi-\arcsin \left|\frac{N_{\mathrm{dp}}}{N}\right|, N_{\mathrm{dp}}>0
\end{array}\right.
$$

where $\gamma_{\mathrm{mh}}$ is the angle between the high side unit-vector and the binormal unit-vector, degrees; $\gamma_{\mathrm{pm}}$ is the angle between the binormal unit-vector and the contact direction, degrees.

The wear location angle becomes $\gamma_{\mathrm{h}}=\gamma_{\mathrm{mh}}+\gamma_{\mathrm{pm}}$, which can be used to determine the casing wear location.

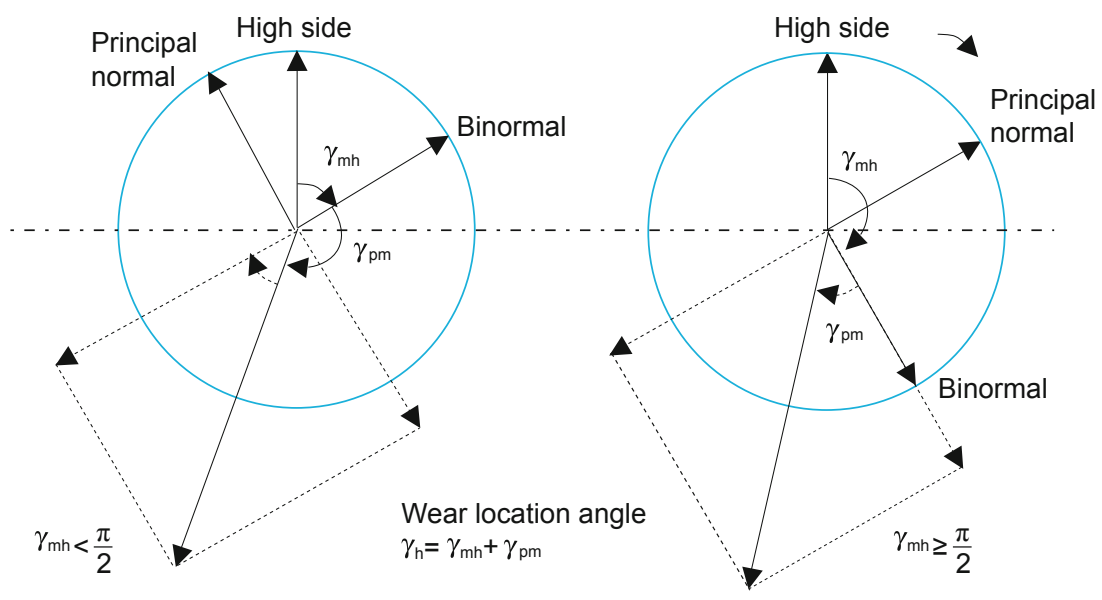

Fig. 3 Schematic of wear location angle

\section{Case study}

In order to evaluate the casing wear in well HZ25-45 and predict the casing wear of other planned wells so as to decide whether the reducers and protectors are needed or not in the HZ25-4 Oilfield, the South China Sea, no casing protection measures were taken when the ø215.9 $\mathrm{mm}$ hole section (five wellbores formed successively in well HZ254-5) was drilled and caliper logging was made for the upper part of $\varnothing 244.5 \mathrm{~mm} \mathrm{N80} \mathrm{casing} \mathrm{after} \mathrm{cementing} \varnothing 177.8 \mathrm{~mm}$ liner for well HZ25-4-5. Based on the models mentioned in the paper, a wear analysis of $ø 244.5 \mathrm{~mm}$ casing used in well
HZ25-4-5 was done to obtain key parameters of the casing wear prediction and then the casing wear of the planned well HZ25-4-6 was predicted without the drill pipe casing protectors.

The cumulative length of $ø 215.9 \mathrm{~mm}$ sections was $3,899.8$ $\mathrm{m}$, and the density of oil-based mud (OBM) was $1.1 \mathrm{~g} / \mathrm{cm}^{3}$. The OD of the tool joint was $177.8 \mathrm{~mm}$ and the ID of $\varnothing 244.5$ $\mathrm{mm}$ casing was $220.5 \mathrm{~mm}$ (casing wall thick of $11.99 \mathrm{~mm}$ ). The friction factor was taken as 0.1 according to the field data. For the inversion calculation of CWF, the drillstring was divided into 1-m-long elements and the calculation was repeated with a changed CWF until the calculated groove 
depths of worn casing matched the survey values (Reiber et al, 1999). The inverted value of CWF was $4.0 \times 10^{-12} \mathrm{~Pa}^{-1}$ for well HZ25-4-5 (see Fig. 4).

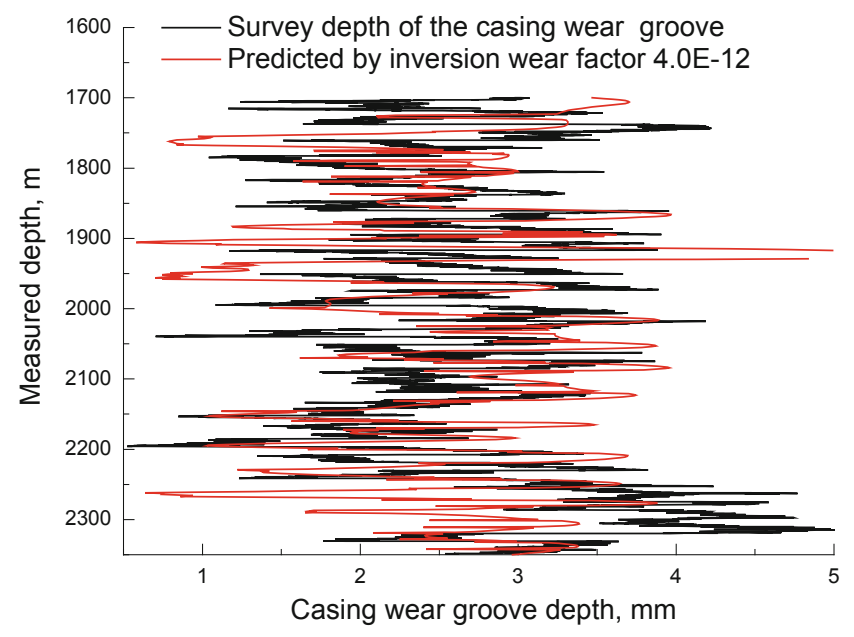

Fig. 4 Inversion of casing wear factor

Actual measurements while drilling and well survey data of the final hole were used to analyze CWGD in the drilled well. Average values of actual drilling parameters and the designed trajectory data were used for the casing wear analysis in the planned well. The ratio of the maximum CWGD in the drilled well to that in the planned well is 1.56 as shown in Fig. 5. Therefore, The ratio 1.56 may be taken as the correction factor for the maximum CWGD in the planned well.

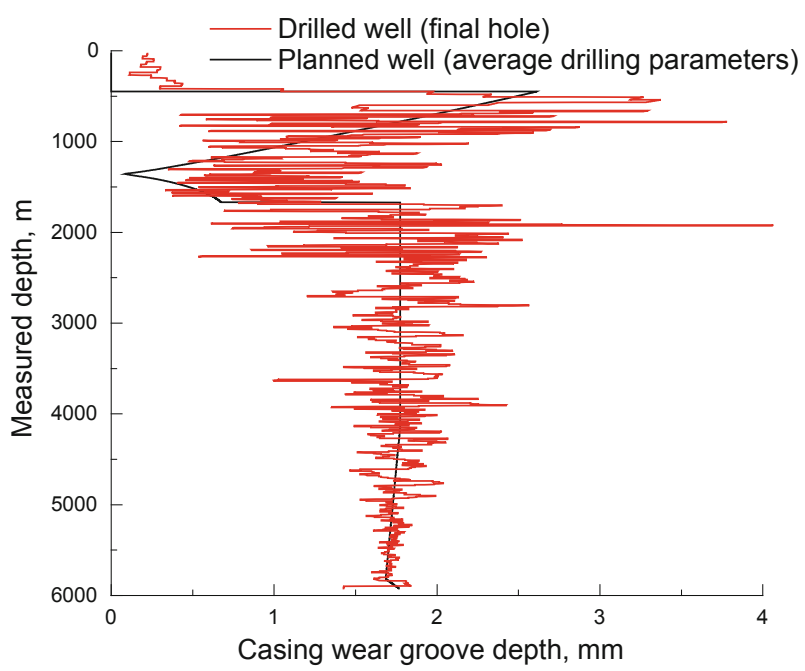

Fig. 5 CWGD comparison diagram for well HZ25-4-5

The structure of planned well HZ25-4-6 is similar to that of the drilled well HZ25-4-5. The ø244.5 mm casing wear is mainly caused during drilling of ø215.9 mm and ø152.4 mm hole sections. The maximum wellbore length is $1,720 \mathrm{~m}$ and average WOB is $44.45 \mathrm{kN}$ in the $\varnothing 215.9 \mathrm{~mm}$ section, and the maximum wellbore length is $397.79 \mathrm{~m}$ and the average WOB is $22.23 \mathrm{kN}$ in the $\varnothing 152.4 \mathrm{~mm}$ section. The average ROP is
$10 \mathrm{~m} / \mathrm{h}$ and the average RPM is $120 \mathrm{rpm}$ in both sections. Thus, the maximum CWGD is $2.73 \mathrm{~mm}$ and the maximum correction depth is $4.26 \mathrm{~mm}$. From the results of casing wear prediction, size changes of the tool joint should be taken into account, or the predicted casing wear depth may be smaller in the deep hole section (see Fig. 6).

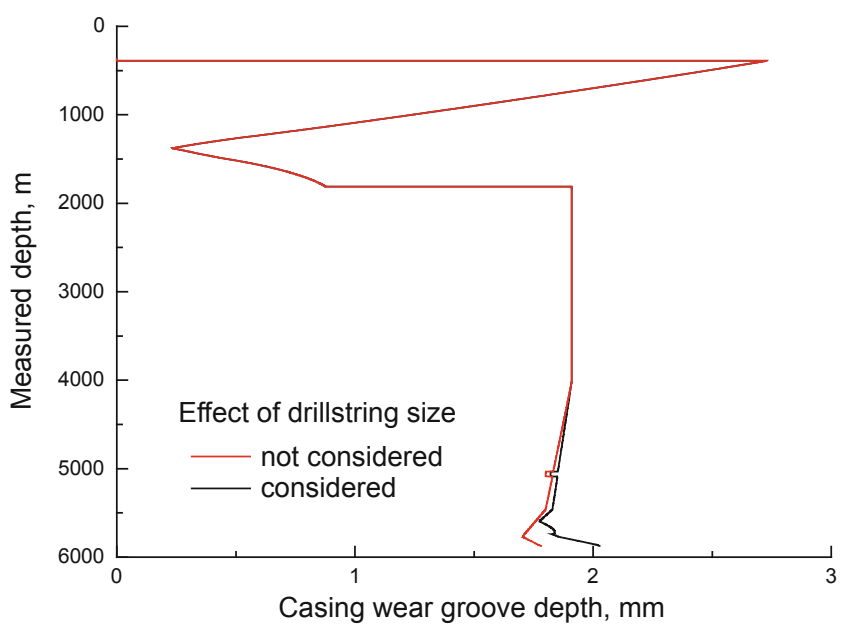

Fig. $6 ø 244.5 \mathrm{~mm}$ casing wear prediction in well HZ25-4-6

There is another way to solve the problem in which the predicted depths of casing wear groove are always less than those obtained from the actual survey due to hole anomaly in an actual well. To better represent the drag \& torque in an actual well, the artificial tortuosity can be added to the planned well. Four tortuosity models are commonly used, including sine wave, helical, random inclination \& azimuth, and random inclination dependent on azimuth (Rezmer-Cooper et al, 1999; Samuel et al, 2005). In this paper, the azimuth simulation used the sine wave method and inclinations were calculated by the random method. Further adjustment to inclination was repeated to keep dogleg severity within a certain range to avoid human-induced anomalies. The results show that the simulated contact forces match closely with those calculated from the actual well path surveys when tortuosity is applied to the planned well for well HZ25-4-5 (see Fig. 7). With the same method to simulate

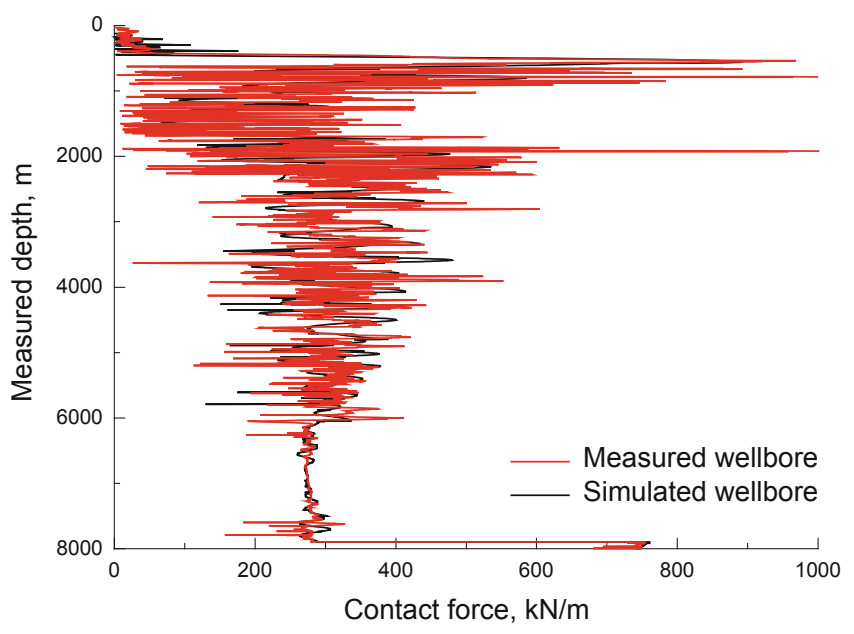

Fig. 7 Contact force simulations for well HZ25-4-5 
the well trajectory data and to predict the casing wear for well HZ25-4-6, the maximum CWGD ranges from $3.6 \mathrm{~mm}$ to $4.3 \mathrm{~mm}$ with different simulated well trajectory data. Fig. 9 illustrates the CWGD calculated by the simulated curve shown in Fig. 8.

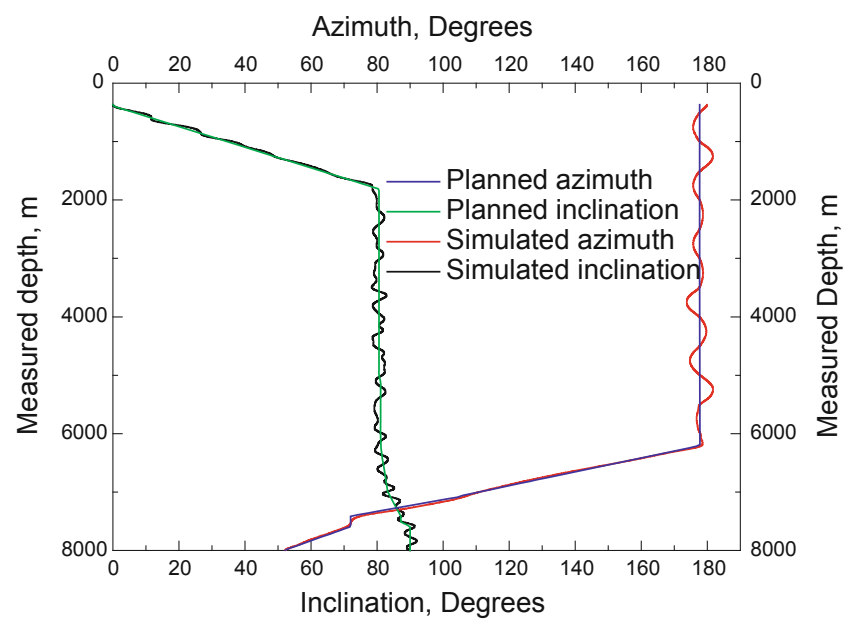

Fig. 8 Planned path and well path with tortuosity of HZ25-4-6

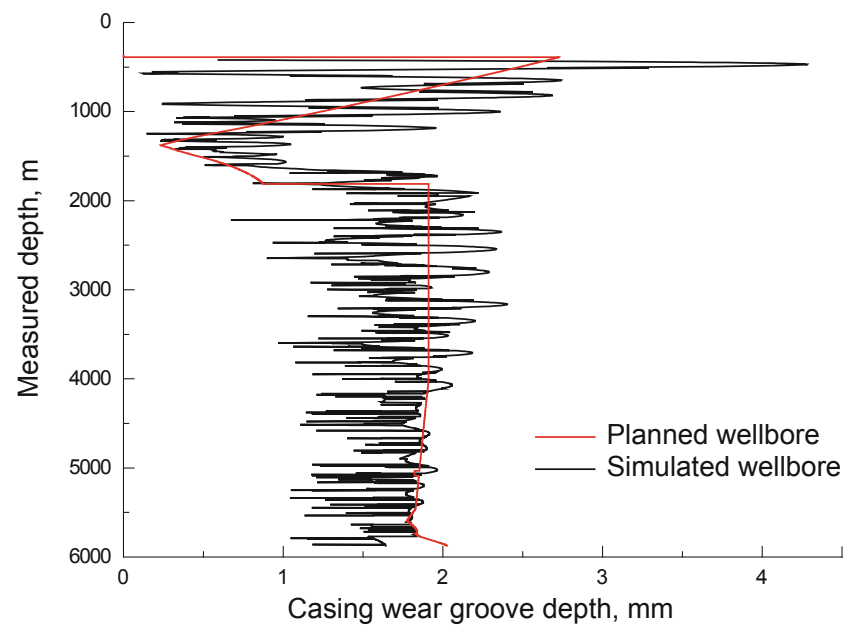

Fig. $9 \varnothing 244.5 \mathrm{~mm}$ casing wear prediction for well HZ25-4-6 with simulated well trajectory

\section{Conclusions}

1) At the steady-state wear stage, the wear-efficiency model can be used to predict the casing wear quantitatively. The inversion value of CWF from the survey data in the drilled wells can be used to predict the casing wear in the adjacent wells to be drilled under similar conditions and the predicted results are good.

2) Dynamic cumulation of the casing wear area and quantitative calculation of the casing wear location angle can be used to predict the groove depth and the locations of the casing string wear.

3) The geometry of a casing wear groove has a great impact on the wear groove depth. Size changes of drillstrings may result in a sudden change in the casing wear mode even if the conditions of friction \& wear are unchanged. Therefore, the effect of drillstring size on the casing wear should be taken into account in the casing wear prediction because they are unavoidable in drilling \& completion operations.

4) When simulating the casing wear in a planned well, it is necessary to make a reasonable correction to the predicted depth of the casing wear groove using scientific inversion of casing wear factor from the drilled well because there are differences between the actual drilled well and the planned well .

\section{Acknowledgements}

The authors are grateful for the financial support from the national projects (Grant No.: 2009ZX05009-005 and 2010CB226703).

\section{References}

Archard J F. Wear theory and mechanism. In: Wear Control Handbook. Edited by Peterson M B and Winer W O. New York: American Society of Mechanical Engineers. 1980. 35-88

Bradley W B and Fontenot J E. The prediction and control of casing wear. SPE Journal of Petroleum Technology. 1975. 27(2): 233-245 (Paper SPE 5122)

Gao D L. Down-hole Tubular Mechanics and Its Applications. Dongying: China University of Petroleum Press. 2006. 80-82 (in Chinese)

Gao D L, Tan C J and Tang H X. Limit analysis of extended reach drilling in South China Sea. Petroleum Science. 2009. 6(2): 166-171

Gao D L and Xu B Y. Principal Equations of Flexible Drillstring Movement from China Postdoctoral Collection of Thesis (No. 4 Set). Edited by Wang G Q. Beijing: Peking University Press. 1991. 347-381 (in Chinese)

Hall R W, Garkasi A, Deskins G, et al. Recent advances in casing wear technology. Paper SPE 27532 presented at SPE/IADC Drilling Conference, 15-18 February 1994, Dallas, Texas

Hall R W and Malloy K P. Contact pressure threshold: An important new aspect of casing wear. Paper SPE 94300 presented at SPE Production Operations Symposium, 16-19 April 2005, Oklahoma City, Oklahoma

Huq $\mathrm{M} \mathrm{Z}$ and Celis J P. Expressing wear rate in sliding contacts based on dissipated energy. Wear. 2002. 252 (5-6): 375-383

Juvkam-Wold $\mathrm{H} \mathrm{C}$ and Wu J. Casing deflection and centralizer spacing calculations. SPE Drilling Engineering. 1992. 7(4): 268-274 (Paper SPE 21282)

Reiber F, Vos B E and Eide S E. On-line torque \& drag: A real-time drilling performance optimization tool. Paper SPE 52836 presented at SPE/IADC Drilling Conference, 9-11 March 1999, Amsterdam, Netherlands

Rezmer-Cooper I, Chau M, Hendricks A, et al. Field data supports the use of stiffness and tortuosity in solving complex well design problems. Paper SPE 52189 presented at SPE/IADC Drilling Conference, 9-11 March 1999, Amsterdam, Netherlands

Samuel G R, Bharucha K and Luo Y. Tortuosity factors for highly tortuous wells: A practical approach. Paper SPE 92565 presented at SPE/IADC Drilling Conference, 23-25 February 2005, Amsterdam, Netherlands

Schoenmakers J M. Prediction of casing wear due to drilllstring rotation: Field validation of laboratory simulations. SPE Drilling Engineering. 1987. 2(4): 375-381 (Paper SPE 14761)

Tan C J, Gao D L, Tang H X, et al. The method of casing wear prediction for Liuhua mega-extended-reach wells in South China Sea. Oil 
Drilling \& Production Technology. 2006. 28(3): 1-3 (in Chinese)

White J P and Dawson R. Casing wear: Laboratory measurements and field predictions. SPE Drilling Engineering. 1987. 2(1): 56-62 (Paper SPE 14325)

Williamson J S. Casing wear: The effect of contact pressure. Journal of Petroleum Technology. 1981. 33(12): 2382-2388 (Paper SPE 10236)

Yang L J. A methodology for the prediction of standard steady-state wear factor in an aluminium-based matrix composite reinforced with alumina particles. Journal of Materials Processing Technology. 2005. (162-163): 139-148

Yu L, Zhang L B, Fan J C, et al. The research on calculation method of casing wear caused by drill-pipe revolution. Drilling \& Production Technology. 2004. 27(4): 66-69 (in Chinese)

(Edited by Sun Yanhua) 